\title{
The report of tumor resection prosthesis infection due to Sphingomonas paucimobilis: A case report
}

\section{Sphingomonas paucimobilis kaynaklı tümör rezeksiyon protezi enfeksiyonu: Vaka sunumu}

\author{
Recep Öztürk ${ }^{1}$, Murat Aydın², Murat Arıkan ${ }^{1}$, Güray Toğral ${ }^{1}$, Güle Aydın ${ }^{3}$ Bedii Şafak Güngörr ${ }^{1}$ \\ ${ }^{1}$ Department Of Orthopaedics And Traumatology, Oncology Training And Research Hospital, Ankara, Turkey \\ ${ }^{2}$ Afyonkarahisar Suhut Public Hospital Medicine Department Of Orthopedics And Traumatology, \\ Afyonkarahisar, Turkey \\ ${ }^{3}$ Department Of Clinical Microbiology And Infectious Diseases, Afyonkarahisar State Public Hospital \\ Afyonkarahisar, Turkey
}

Dergiye Ulaşma Tarihi: 27/09/2015 Dergiye Kabul Tarihi: 04/10/2015 15 DOI: 10.5505/aot.2016.5707

\section{ÖZET}

Sphingomonas paucimobilis genellikle altta yatan bir komorbit hastalık ile beraber patojenite gösteren firsatçı bir enfeksiyon ajanıdır. Sphingomonas paucimobilis bakteriyemi, ventilatör ilişkili pnömoni, intravasküler kateter ilişkili enfeksiyonlar, menenjit, peritonit, osteomyelit, septik artrit, postoperatif endoftalmit, plevral ampiyem, splenik apse, üriner trakt enfeksiyonları ve bilier trakt enfeksiyonları da dahil olmak üzere çok çeşitli enfeksiyonlarla ilişkilendirilmişsir.

$\mathrm{Bu}$ vaka takdiminde osteosarkoma nedeni ile endoprostetik tümör rekonstrüksiyonu yapılan bir olguda, Sphingomonas paucimobilis'in neden olduğu prostetik eklem enfeksiyonu bildirilmiştir. $\mathrm{Bu}$ olgu S. paucimobilis'in neden olduğu, tümör rezeksiyon protezi eklem enfeksiyonu raporudur.

Anahtar Kelimeler: Sphingomonas paucimobilis, Endoprostetik enfeksiyon, Osteosarkoma

\section{ABSTRACT}

Sphingomonas paucimobilis is an opportunistic infectious agent that generally shows its pathogenicity by accompanying an underlying comorbid disease. It is recognized that Sphingomonas paucimobilisis associated with many infections, including: bacteremia, ventilator related pneumonia, intravascular related catheter infections, meningitis, peritonitis, osteomyelitis, septic arthritis, postoperative endophthalmitis, pleural empyema, splenic abscess, urinary tract infections and biliary tract infections.

The present report described a prosthetic joint infection, caused by Sphingomonas paucimobilis, in a patient who had endoprosthetic tumor reconstruction due to osteosarcoma. It chronicles the prosthetic joint infection with endoprosthetic tumor reconstruction in the literature caused by S. paucimobilis.

Key words: Sphingomonas paucimobilis, Endoprosthetic infection, Osteosarcoma.

\section{Introduction}

As a result of repetitive surgical interventions and elongated antibiotic use, the treatment of prosthetic joint infections is a complication with high morbidity and mortality. Bacteriological diagnosis is a very important aspect of treatment success with prosthetic joint infections. A disease caused by microorganisms, cultured via bacteriological diagnosis, may be investigated by the definition of the species, which have caused prosthetic infection, and by its antibiotic susceptibility (1). Clinical failure rates are high in interventions performed under empirical treatments without clinicians culturing the causative agent (2).

The present case is a report of a patient who had a prosthetic joint infection after the tumor resection, caused by Sphingomonas paucimobilis bacillus, and who was cured after appropriate antibiotic use. Sphingomonas paucimobilis bacillus was cultured microbiologically, following long and challenging procedures.

\section{Case Report}

A twenty-two year old male patient applied to our hospital with a purulent discharge through a sinus tract in the anteromedial incision line on his left knee. In the physical examination, there was a sinus tract, and a tibial component of tumor resection prosthesis in depth with a prolene mesh over it, which remained from the previous operation (Figure - 1). The patient's vital signs were within normal limits. There was no sensorial deficit in his feet dermatomes in the neurological examination, but he had a 
dropped foot due to a peroneal nerve motor lesion. In the radiological examination, alongstemmed tumor resection prosthesis in his knee joint was evident (Figure - 2). Stability of the connection and its components was adequate in both the physical and radiological examinations. The erythrocyte sedimentation rate was $36 \mathrm{~mm} / \mathrm{h}, \mathrm{C}$-reactive protein was 28 $\mathrm{mg} / \mathrm{dl}$ and the hemogram and biochemical tests were within normal limits.

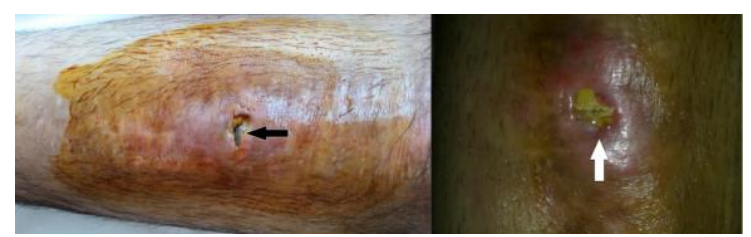

Figure 1: Local skin changes involving sinus tract on the incision line and prolene mesh in the depth of sinus tract are observed, seen as white and black arrow

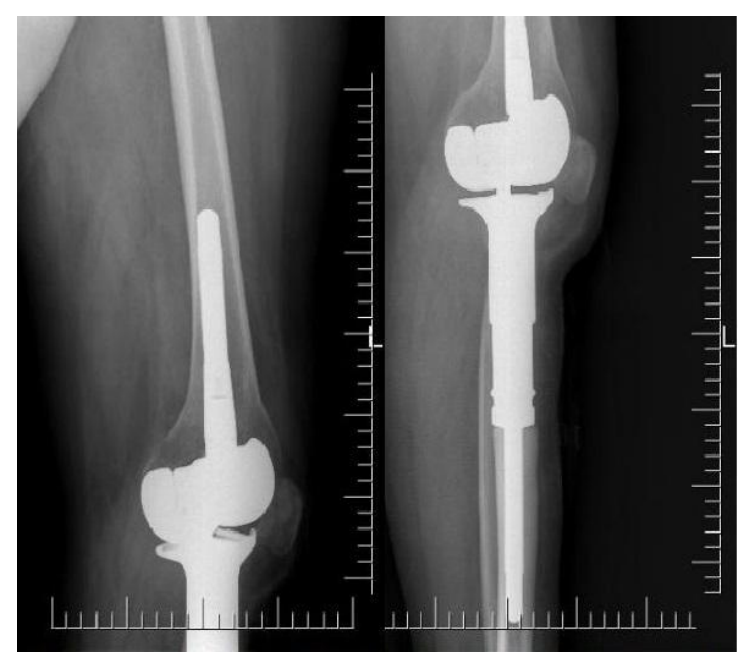

Figure 2: Radiological findings of the prosthetic joint developed after tumor resection, and distal femoral and also tibial proximal tumor prosthesis implantation,

The patient had had an incisional biopsy, from which followed a diagnosis of destructive lesion in the proximal of his left tibia, at another center 24 months previously, and he was diagnosed with telangiectatic osteosarcoma after histological examination. $\mathrm{He}$ received three courses of neoadjuvant chemotherapy, after which an extensive tumor resection and reconstruction with a tumor resection prosthesis was performed. $\mathrm{He}$ received one course of adjuvant chemotherapy following the operation. After the adjuvant chemotherapy, hyperemia, increased temperature and then a purulent discharge were observed at the incision line. The first laboratory results of the case were $\mathrm{ESR}=84$ $\mathrm{mm} / \mathrm{h}, \mathrm{CRP}=58 \mathrm{mg} / \mathrm{dl}$. In the microbiological examination, Corynebacterium sp. was grown as the causative agent in swab culture obtained from the wound site. When the same procedure was performed 10 days later to rule out skin contamination, no microorganism was grown, and the growth of Corynebacterium sp. was accepted as skin contamination. No culture growth was determined in other swab cultures taken from the sinus tract at the same time. As no pathogen was grown, wide spectrum antibiotic treatment was started with teicoplanin $1 * 400$ and ciprofloxacin $2 * 200$, and maintenance treatment was given for six weeks. However, there was no clinical recovery, despite the wide-spectrum antibiotic treatment, and the discharge continued.

As there was no clinical recovery, the same center planned a two-stage debridement plus antibiotic spacer application and revision endoprosthesis operation. Prosthetic implants were removed and a manufactured antibiotic impregnated spacer was implanted during the same operation. No sign of local infection was determined during the periodical postoperative examinations, and sedimentation and CRP returned to normal values.

As postoperative ESR and CRP values were normal three times during postoperative controls, the manufactured spacer was removed and endoprosthetic implant reconstruction was performed in the second operation.

When the patient applied to our clinic on the postoperative Day 20, he had wound discharge and a purulent sinus tract. As there was no culture growth in previous swab samplings, it was decided to obtain the tissue sample for culture under the sterile operating room conditions. Under deep sedation, biopsy materials were obtained from the sinus tract, and tissue biopsy was performed from deep layers using blunt incisions. Also a piece of the prolene mesh, which had been used to close the fascia defect, was biopsied. Both samples were inoculated immediately into an appropriate microbiological culture media for microbiological examination.

In the microbiological examination, Sphingomonas paucimobilis was grown in EMB agar. An antibiogram test revealed that the causative species was resistant to piperacillin, third generation cephalosporin, sulbactam from beta lactamase inhibitors, and 
fluoroquinolones, and it was moderately sensitive to fourth generation cephalosporin, carbapenem, and meropenem. It was sensitive to aminoglycosides, poymyxins and imipenem. Antibiotic treatment of the patient was specified to the target with the help of infectious diseases consultation, and it was ordered as meropenem $3 * 1 \mathrm{~g}$, teicoplanin $1 * 400 \mathrm{mg}$ intravenous infusion. After 10 days, it was observed that the discharge volume had decreased, but nevertheless it was continuing. On Day 18 of the treatment, ESR was 18 $\mathrm{mm} / \mathrm{h}$, and CRP was $16 \mathrm{mg} / \mathrm{dl}$. Ciprofloxacin $2 * 1 \quad 750 \mathrm{mg}$ was started as intravenous infusion on treatment Day 10. Discharge at the wound site was decreased, but continued until treatment Day 20, and ESR was $11 \mathrm{~mm} / \mathrm{h}$, and CRP was $9 \mathrm{mg} / \mathrm{dl}$. Therefore, ciprofloxacin and meropenem were stopped, and teicoplanin at the same dose with colistin $150 \mathrm{mg} 2 * 1$ were administered as an intravenous infusion. The discharge stopped after 10 days of treatment with colistin, and local signs were completely recovered (Figure - 3). After the first culture, no growth was reported in swab samples obtained from the sinus tract. The latest ESR was $16 \mathrm{~mm} / \mathrm{h}$, and CRP was $6 \mathrm{mg} / \mathrm{dl}$. After the discharge was stopped at the wound site, and the patient made a complete clinical recovery, and a venous flap grafting was performed at the wound site by the plastic and reconstructive surgery clinic.

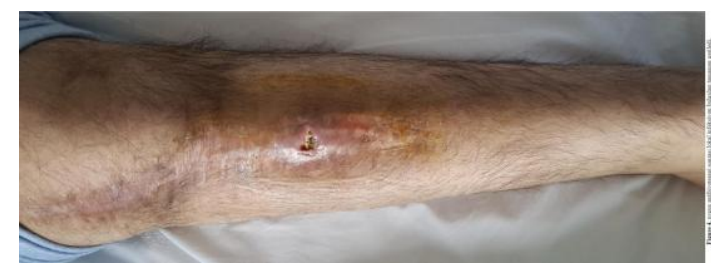

Figure 3: It is observed that wound tissue has nearly complete recovered except $1 * 1 \mathrm{~cm} 2$ area on the first wound following the appropriate antibiotic treatment after the antibiogram but local infection signs have totally recovered.

\section{Tartışma ve Sonuç}

The most common and important causative agents in prosthetic joint infections are gram-positive cocci Staphylococcus aureus and Staphylococcus epidermidis. Coagulase negative Staphylococcus epidermidis (S. epidermidis) are responsible for $30-43 \%$, and S. aureus is responsible for $12-23 \%$ of prosthetic infections. Streptococci, enterococci, gram-negative bacilli, anaerobic bacilli are the other causative microorganisms (3).

There are three basic milestones to achieve the successful treatment of an infected prosthesis. These are: eligible patient selection, and evaluation of patient related factors, appropriate surgical technique, and selection of the most appropriate antibiotics (4). In the present case, clinical success could not be achieved despite the appropriate surgical technique, because the causative agent could not be cultured.

There are many treatment options in treating infected prosthesis. These can be named as: suppression by using antibiotics, debridement and prosthesis protection, single stage revision, double stage revision, resection arthroplasty, arthrodesis and amputation (5). In the presented case, initially antibiotic suppression was tried, and then when the case did not respond, a two-stage revision operation was performed.

Sphingomonas paucimobilis is a gramnegative aerobic non-fermentative bacillus without spores, which was oxidase and catalase positive, and had yellow pigments, and was previously known as pseudomonas paucimobilis (6). S. paucimobilis is widely dispersed in nature, especially in water and soil. It is present in the water system, on respiratory treatment equipment, and in humidifying systems (7). It has been reported that $\mathrm{S}$. paucimobilis is associated with many different infections including bacteremia, ventilator related pneumonia, intravascular catheter infections, meningitis, peritonitis, osteomyelitis, septic arthritis, postoperative endophthalmitis, pleural empyema, splenic abscess, urinary tract infections, and biliary tract infections (8).

It has been reported that the microorganism has been isolated from various clinical samples, such as blood, urine, sputum, and cerebrospinal fluid (9). In the presented case, Sphingomonas paucimobilis was grown in the culture of the tissue biopsy sample obtained from the sinus tract. In the literature review, it was determined that $\mathrm{S}$. paucimobilis infection had always been defined as accompanying different comorbidities, such as malignancy, diabetes mellitus, alcoholism, hepatic cirrhosis, late stage renal failure, chronic obstructive pulmonary disease, burn wounds, and acquired immune deficiency syndrome (10). In the presented case, the 
comorbidity was tibial proximal osteosarcoma, in addition to secondary immune suppression due to the previous chemotherapy.

In the literature review, there are four cases in which $\mathrm{S}$. paucimobilis has caused bone and joint infections. It was reported that two out of four cases with bone and joint infections were immunosuppressed, and two were immunocompetent, while there was septic arthritis in one case, and osteomyelitis in three, and secondary septic arthritis accompanied by osteomyelitisin one case (9,11,13-15) and besides these a few cases was reported with orthopedic implants which was caused by S. paucimobilis specified with primary prosthetic joint implantation (16-17).

As yet there is no standard procedure for antibiotic sensitivity of S. paucimobilis. Based on in-vitro sensitivity studies, case specific antibiotherapy indication was required, because antibiotic resistance was reported differently in many articles (9). Our case was resistant to piperacillin, third generation cephalosporin, sulbactam, fluoroquinolone; moderately susceptible to fourth generation cephalosporin, and meropenem from carbapenem; and susceptible to aminoglycosides, polymyxins, and imipenem.

In conclusion, S. paucimobilis is a rare but opportunistic pathogen that may appear as nosocomial or a population based infectious pathogen; and although it has low virulence and is non-fatal, it may cause serious problems such as prosthetic joint infection. The presented case is the prosthetic infection case with endoprosthetic tumor reconstruction caused after an orthopedic bone and joint replacement surgery by $\mathrm{S}$. paucimobilis.

\section{Conflict of Interest: None}

\section{References}

1. Cui Q, Mihalko WM, Shields JS, Ries M, Saleh KJ. Antibiotic-impregnated cement spacers for the treatment of infection associated with total hip or knee arthroplasty. J Bone Joint Surg Am 2007;89:871-882

2. Bjerke-Kroll BT, Christ AB, McLawhorn AS, Sculco PK, Jules-Elysee KM, Sculco TP. Periprosthetic joint infections treated with two-stage revision over 14 years: an evolving microbiology profile. J Arthroplasty 2014;29:877-82
3. Yabuuchi E, Yano I, Oyaizu H, Hashimoto Y, Ezaki T, Yamamoto H. Proposals of Sphingomonas paucimobilis gen. nov. and comb. nov., Sphingomonas parapaucimobilis sp. nov., Sphingomonas yanoikuyae sp. nov., Sphingomonas adhaesiva sp. nov., Sphingomonas capsulata comb. nov. and two genospecies of the genus Sphingomonas. Microbiol Immunol 1990; 34: 99 119

4. Gil-Diaz A, Estevez-Dominguez R, DaryananiDaryanani R, Gil-Reyes J, Monzon-Moreno C. Fever of unknown origin in a young man. Ir J Med Sci 2014;183(3):461-2

5. Cheong HS, Wi YM, Moon SY, et al. Clinical features and treatment outcomes of infections caused by Sphingomonas paucimobilis. Infect. Control. Hosp. Epidemiol 2008;29:990-992

6. Pascale R, Russo E, Esposito I, Leone S, Esposito S. Sphingomonas paucimobilis osteomyelitis in an immunocompetent patient. A rare case report and literature review. New Microbiol 2013;36(4):423-6

7. Lin JN, Lai $\mathrm{CH}$, Chen $\mathrm{YH}$, et al. Sphingomonas paucimobilis bacteremia in humans: 16 case reports and a literature review. J. Microbiol. Immunol Infect 2010;43:35-42

8. Aggarwal VK, Bakhshi H, Ecker NU, Parvizi J, Gehrke T, Kendoff D. Organism profile in periprosthetic joint infection: pathogens differ at two arthroplasty infection referral centers in Europe and in the United States. J Knee Surg 2014;27(5):399406

9. Fink B. Revision of late periprosthetic infections of total hip endoprostheses: pros and cons of different concepts. Int J Med Sci 2009;6:287-95

10. Parvizi J, Zmistowski B, Adeli B. Periprosthetic joint infection: treatment options. Orthopedics 2010;33:659

11. Deveci MA, Şener E, Şimşek SA, Two-stage revision in the treatment of prosthesis-related infections TOTBID Journal 2011;10(4):312-318

12. Souto A, Guinda M, Mera A, Pardo F. Septic arthritis caused by Sphingomonas paucimobilis in an immunocompetent patient. Reumatol. Clin. 8, 378-37

13. Pascale R, Enrico E, Esposito I, Leone S, Esposito S. Sphingomonas paucimobilis osteomyelitis in an immunocompetent patient. A rare case report and literature review. New Microbiologica. 2013; 36:423426, 2013

14. Charity RM, Foukas AF. Osteomyelitis and Secondary Septic Arthritis Caused by Sphingomonas paucimobilis, Foukas Infection 2005; 33: 93-95

15. Araújo O, Vidal F, Tapiol J, Richart C. Osteomyelitis caused by Sphingomonas paucimobilis. Enferm Infecc Microbiol Clin. 2000;18(5):247

16. Lass R, Giurea A, Kubista B, Hirschl AM, Graninger W, Presterl E, Windhager R, Holinka J. Bacterial adherence to different components of total hip prosthesis in patients with prosthetic joint infection. Int Orthop. 2014;38(8):1597-602

17. Esteban J, Gomez-Barrena E, Cordero J, Martín-deHijas NZ, Kinnari TJ, Fernandez-Roblas R. Evaluation of quantitative analysis of cultures from sonicated retrieved orthopedic implants in diagnosis of orthopedic infection. $\mathrm{J}$ Clin Microbiol. 2008;46(2):488-92 